\title{
A Psychosocial Approach to Stakeholder Participation in Environmental Problem Solving. The Case of the Contaminated Site Cleanup at Mapua, New Zealand
}

\author{
Daniel John Ducker (Corresponding author) \& Te Kipa Kepa Brian Morgan \\ Department of Civil and Environmental Engineering \\ Faculty of Engineering, New Zealand \\ E-mail: d.ducker@auckland.ac.nz
}

Received: July 31, 2012 Accepted: August 18, 2012

doi:10.5296/emsd.v1i2.2170 ～URL: http://dx.doi.org/10.5296/emsd.v1i2.2170

\begin{abstract}
Problem Statement: Stakeholder participation has been widely touted as a necessary means to help resolve complex environmental issues, however there are deficiencies in current theory regarding the basis of effective participatory processes, particularly with regard to psychosocial components of interaction. Approach: A detailed case investigation is undertaken of a typical example of technoscientific problem solving - the cleanup of a contaminated site in Mapua, New Zealand. Results: Analysis highlights the deficiencies of the traditional problem solving approach which limits stakeholder participation, leading to negative emotional reactions and hampering attempts at robust, successful environmental problem solving. In contrast, a model of effective stakeholder participation is developed, based on three principle themes of empathy, understanding and empowerment. These three themes provide a new formulation for stakeholder participation environmental problem solving and a means of questioning the systems which currently exist for addressing environmental issues.
\end{abstract}

Keywords: Environmental psychology, problem solving, psychosocial, empathy, understanding, empowerment 


\section{Introduction}

Stakeholder participation is now widely acknowledged as an important component of contemporary environmental problem solving practice (e.g. NRC, 2008; M. S. Reed, 2008; Stringer, Reed, Dougill, Rokitzki, \& Seely, 2007). Although there is substantial diversity in how participation has been defended and understood, scholars of stakeholder participation recognise three primary imperatives: normative, substantive, and instrumental (Delgado, Kjolberg, \& Wickson, 2011; Fiorino, 1990; Stirling, 2008).

Normative imperatives view participation as simply "the right thing to do" (Stirling, 2008). Affected parties, it is thought, "are the best judge of their own interests" (Fiorino, 1990; Laird, 1993). In this manner, participation is hoped to promote fairer, more just environmental decisions (Laird, 1993). The substantive imperative asserts that stakeholders provide useful "extended facts" and values which contribute to better problem understanding (Funtowicz \& Ravetz, 1993). Proponents argue that broad involvement in environmental risk issues enables solutions to be better adapted to local socio-cultural and environmental conditions (M.S. Reed, Dougill, \& Taylor, 2007). Thus, substantive aspects of participation stress improvements to the quality of environmental decisions. Instrumental imperatives relate to the outcomes of participation. Prominent instrumental outcomes include reduction or avoidance of conflict, establishment of common ground and trust between participants, generating long-term support and active implementation of decisions thereby reducing implementation costs (Creighton, 2005).

Although a wide variety of benefits have been identified, a number of concerns have been raised surrounding the ability of stakeholder participation to meet expectations (Abels, 2007; Sunstein, 2006; Ventriss \& Kuentzel, 2005). While participatory approaches have been enthusiastically adopted, enthusiasm must be tempered with the knowledge that practically, the results of participation have been mixed (Irvin \& Stansbury, 2004). Stakeholder participation advocates claim that implementation challenges may be rectified by a better understanding of participatory theory and practice (Bishop \& Davis, 2002; O'Faircheallaigh, 2010). The purpose of this article therefore is to explore psychosocial considerations in stakeholder participation and to extend current models.

\section{Models of Stakeholder Participation}

A number of different models have been formulated to describe stakeholder participation. Three of the dominant models include the information flow model, the power model, and the deliberative model. The following provides a short critical analysis of each of the models.

\subsection{Information flow model}

Some theorists are content to conceptualise stakeholder participation in terms of information flow between agents. For example, Rowe and Frewer (2005), in one of the most widely cited references to stakeholder participation, draw a distinction between communication (a flow of information from project sponsors to stakeholders), consultation (a flow of information from stakeholders to project sponsors) and stakeholder participation (a two way flow of information between project sponsors and stakeholders) (Figure 1). From this perspective, the 


\section{Macrothink}

aim of participation is "to acquire all relevant information from all relevant members of the population (sources) and transfer this to relevant recipients (be these the sponsors or the participants)” (Rowe \& Frewer, 2005).

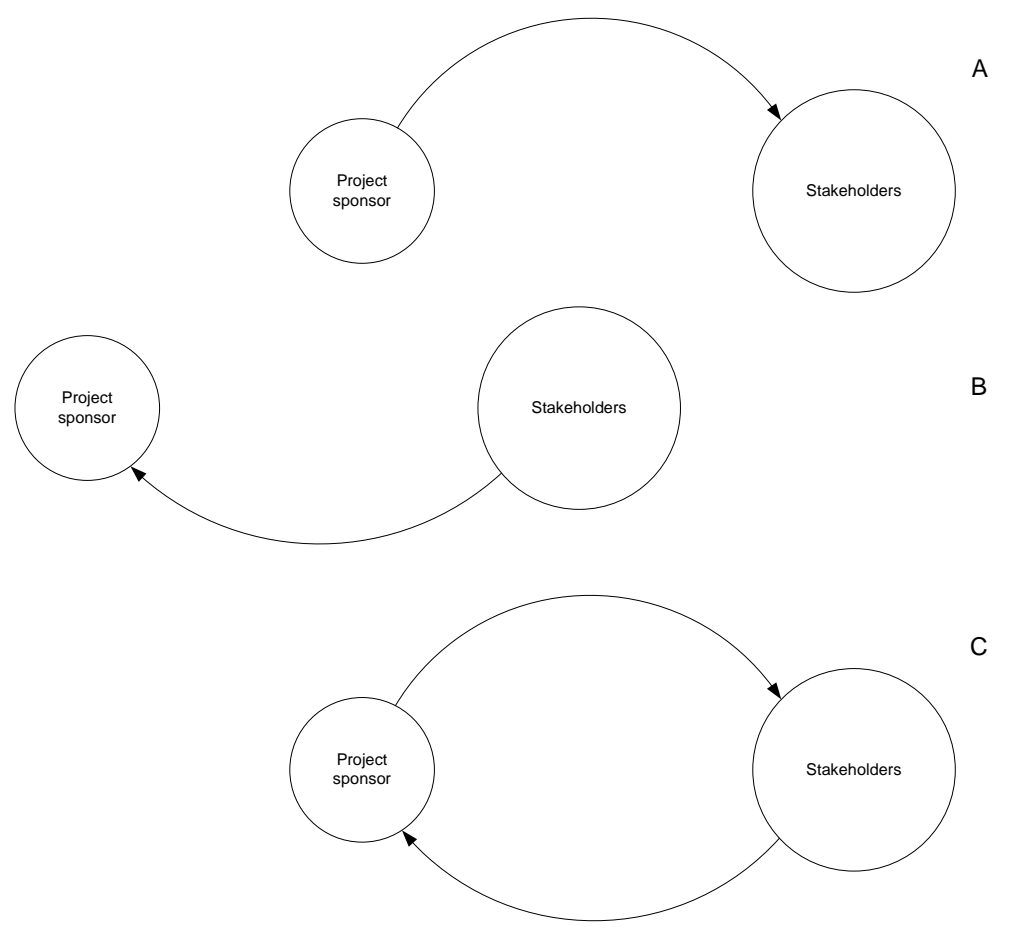

Figure 1. Three forms of engagement as adapted from by Rowe and Frewer (2005): a) Stakeholder communication - Information conveyed from project sponsors to members of the public; b) Stakeholder consultation - Information conveyed from members of the public to project sponsors; c) Stakeholder participation. Two way exchange of information between project sponsors and members of the public.

Treating participation as information flow is useful because it highlights crucial role of feedback. Consequently, the information flow model identifies the necessity of openness and transparency in authentic collaborative inquiry (King, Feltey, \& Susel, 1998). However, an emphasis on 'information' has several weaknesses. Firstly a strict information flow model fails to comprehensively account for important participatory factors. For example, information (communication) is but one component of trust development - a focus on information does not account for the various perceptions which may be present interpreting that information. Secondly, an emphasis on information precludes exploration of the subtleties of interaction. Stakeholder participation is frequently an emotional process, in which participants may passionately advocate particular perspectives according to interest (Harvey, 2009). The information flow model cannot account for emotional aspects. Thirdly, the information flow model barely accounts for power, emphasising the power to control information flow as most critical. However, power may be exerted in other subtler forms yet cannot be incorporated in the information flow model. While a useful theoretical perspective, the information flow model is incapable of providing a comprehensive account of important participation concepts. 


\subsection{Power model}

Alternatively, other theorists insist that use of the term stakeholder participation is only justified when the participants are actively involved and where decision makers are substantially influenced by that involvement (Bishop \& Davis, 2002, p15-17). A number of theorists and practitioners stress the need for involvement to be "meaningful" and "not just data to decision makers elsewhere", the ability to exert influence decisions is often seen as critical (Delgado et al., 2011; Lockie, 2001). Sherry Arnstein advocates in her famous "ladder of participation" a fundamentally egalitarian ideal for meaningful public involvement (Arnstein, 1969). Arnstein's framework details differences in influence on outcome between agency representatives and other participants, framing participation as decision making power (Arnstein, 1969). She claims that "citizen participation is a categorical term for citizen power. It is the redistribution of power that enables the have-not citizens, presently excluded from the political and economic process, to be included in the future". Meaningful participation is explicitly associated with processes which are higher up the rungs of the ladder (Table 1). Similar “ladders” have been proposed by IAP2 (2007) and Pretty (1995).

Table 1. Levels of stakeholder participation (Arnstein, 1969)

\begin{tabular}{|l|l|l|l|}
\hline Level & Type & & Explanation \\
\hline Level 8 & Full control & & Full delegation of all decision-making and actions. \\
\hline Level 7 & $\begin{array}{l}\text { Delegated } \\
\text { power }\end{array}$ & & Some power is delegated. \\
\hline Level 6 & Partnership & & $\begin{array}{l}\text { People negotiate with institutional power holders over agreed } \\
\text { roles, responsibilities and levels of control. }\end{array}$ \\
\hline Level 5 & Placation & & $\begin{array}{l}\text { Power holders still make the decisions but other people's views } \\
\text { have some influence }\end{array}$ \\
\hline Level 4 & Consultation & & $\begin{array}{l}\text { People are given a voice, but no power to ensure their views are } \\
\text { heeded. }\end{array}$ \\
\hline Level 3 & Informing & & $\begin{array}{l}\text { Power holders tell people what is going to happen, is happening, or } \\
\text { has happened. }\end{array}$ \\
\hline Level 2 & Therapy & & As below \\
\hline Level 1 & Manipulation & & $\begin{array}{l}\text { Assumes a passive audience, which is given information that may } \\
\text { be partial or constructed. }\end{array}$ \\
\hline & & & \\
\hline
\end{tabular}

Arnstein's ladder is designed to focus attention on historically disenfranchised groups; her explicit emphasis on power is a pragmatic one. A variety of studies indicate that the results of participation are frequently nullified by power relations at the political level (Birkland, 1999), thus an understanding of power relations is fundamentally important to understanding participation. However, ultimately, an excessive prominence on power has considerable limitations. 


\section{Ml Macrothink}

Firstly, Arnstein assumes that control is a fundamental goal of participation. To the contrary, other researchers have discovered that participation is context dependent and that citizen control may not be ultimately desirable for all parties. For example, Webler and Tuler (2001) investigated attributes of good process according to citizens and discovered a dominant discourse which endorsed responsible leadership, not citizen control. Furthermore, participation is dynamic, however Arnstein's ladder does not recognise the agency of participants who may seek different methods of involvement in relation to different issues and at different times (Tritter \& McCallum, 2006). For instance, potential participants may not wish to be involved at all, or participate in observational or advisory roles during different stages of a contaminated site clean-up.

Secondly, Arnstein's ladder assumes that power has a common basis for users, providers and policymakers and ignores the existence of different relevant forms of knowledge and expertise (Tritter \& McCallum, 2006). An emphasis on power thus limits the potential for sharing experience, knowledge and the harnessing of multiple perspectives inherent in successful stakeholder involvement (Collins \& Ison, 2009; O'Faircheallaigh, 2010).

Finally, like the information flow model, an emphasis on power also neglects emotive aspects of participation.

\subsection{Deliberative Model}

A third model of participation embodies normative desires for deliberative discourse. Webler (1995) builds on the Habermassian notion of communicative rationality (Habermas, 1984), to develop a normative theory of participation based on fairness and competency. Webler (1995) contends that "right" participation encourages multi-way communication; is consensual and non-hierarchical; requires respect for individual autonomy; relies on citizens' reasonableness; and promotes critical self-reflection. While this metaethical stance provides an important contribution to research into stakeholder participation by grounding it in fundamental social theory, it is also sensitive to the inadequacies of Habermassian theory. In particular, it neglects the logical failings of discourse, specifically, the irregularities of cognition and the emotional components of participation. Nevertheless, Webler's rigorous and thoughtful exposition is an important contribution to the field of EPC participation and has been widely adopted (e.g. Kinney \& Leschine, 2002; Palerm, 2000; Santos \& Chess, 2003).

\section{Psychosocial Characteristics of Stakeholder Participation}

Psychosocial considerations are important to stakeholder participation, yet they are rarely acknowledged. The following sections outline four important psychosocial aspects: ideologies, cognition, emotion, and social factors.

\subsection{Ideologies}

Mental models, or ideologies colour the way we perceive, think and act in the world. Our brains are hard wired for learning and over time, we grow to form particular perspectives, or ideologies which help us to make sense of, and function in the world (Miller, 1999). 
Ideologies form the basis for differences of opinion in environment matters and can be so ingrained that they elicit automatic and habitual responses. A range of factors is thought to influence ideological development, significant influences include intrinsic genetics, hormone levels, gender, upbringing, access to education, affluence etc. Many of these factors are of course inter-related, and there is strong evidence for interdependencies between intrinsic (biological) mechanisms, and extrinsic (social) influences (Miller, 1999).

In a world with considerable genetic and cultural diversity, a wide variety of environmental ideologies may be anticipated. However, a broad body of diverse literature suggests there are chiefly two disparate orientations which conflict during environmental problem solving. Although called by various names, for example competitive/cooperative, dominant/indigenous, reductionist/holistic, contemporary/alternative, these two orientations provide a useful entry point into understanding why environmental decision making is so challenging, and often intractable (Harding, Hendriks, \& Faruqi, 2009; Mander, 1991; Miller, 1999; Peet, 2006). Following Worster (1993) and Miller (1999), these are subsequently referred to as Imperial and Arcadian ideologies (Table 2).

The Imperial ideology views life as an individual struggle for existence. The overwhelming emphasis of the Imperial ideology is individualism; thus competition is inevitable and natural. For Imperialists, human beings are chiefly self-interested creatures competing for power. While it is accepted that the primal competitive drive can generate predispositions of aggression, Imperialists also contend that self-interest causes humans to be ingenious, creative and innovative. Thus, the Imperial ideology merges core values of individual self-interest, intrinsic talent and creativity, domination and utilitarianism with strategic or detached reasoning. The culmination of these factors is a hierarchical society focused on economic growth and personal advancement (Miller, 1999, p. 15).

In contrast to the Imperial ideology, the Arcadians emphasise that humans are social animals. Rather than purely individualistic traits, Arcadians focus on pro-social parts of human nature and cooperative pursuits, although they accept that competitiveness is also evident. Arcadians contend that a decentralised partnership society, in harmony with nature, which discourages self-aggrandizement, ought to be societal goals. The Arcadian ideology diverges strongly from the current social model.

Table 2. Comparison of Imperial and Arcadian orientations (following Cotgrove, 1982; Miller, 1999; Pepper, 1996)

\begin{tabular}{|ll|}
\hline Imperial & \multicolumn{1}{c|}{ Arcadian } \\
\hline $\begin{array}{l}\text { Humans are wholly self interested } \\
\text { Humans are naturally aggressive and competitive }\end{array}$ & Humans can be altruistic \\
Humans are capable of only limited caring & Humans are naturally cooperative \\
Risks should be taken to attain rewards & Human are capable of widespread concern \\
Individuals should look after themselves & Caution should be exercised \\
\hline Rational thought is more important than intuition and emotion & We should take care of each other \\
Fact and reasoning can be separated from value and feeling & Emotion and intuition are at least as important as rational thought \\
\hline
\end{tabular}




\begin{tabular}{|c|c|}
\hline \multicolumn{2}{|c|}{ Nature of Society } \\
\hline $\begin{array}{l}\text { Human societies are naturally hierarchical } \\
\text { Decisions should be made by experts: Politicians advised by } \\
\text { scientists }\end{array}$ & $\begin{array}{l}\text { Social hierarchies are naturally egalitarian } \\
\text { We should all be involved in decision making }\end{array}$ \\
\hline The way forward is through representative democracy & The way forward is through direct democracy \\
\hline Material acquisition underlies social progress & $\begin{array}{l}\text { Spiritual quality of life and loving relationships are of utmost } \\
\text { importance }\end{array}$ \\
\hline Separation of spirituality and life, church and state & Spirituality integrated within all aspects of life \\
\hline Economic growth is desirable and can go on forever & Indiscriminate economic growth is bad and should not continue \\
\hline Large scale production and central control are desirable & Small scale production locally controlled is more desirable \\
\hline Current socio-political arrangements are acceptable & There needs to be fundamental socio-political change \\
\hline The best societies are efficient & The best societies are resilient \\
\hline Private ownership is valued & Public ownership is valued \\
\hline Justice based on adversarial process enacted by 'impartial' judges & Justice based on natural law enacted by esteemed peers \\
\hline Future focused & Past, present and future acknowledged \\
\hline Short-term goals & Long-term goals \\
\hline Reverence toward youth & Reverence toward aged \\
\hline \multicolumn{2}{|c|}{ Nature } \\
\hline Nature is hostile and neutral & Nature is benign \\
\hline Mechanistic & Complex and chaotic \\
\hline The natural world contains ample reserves & Earth’s resources are limited \\
\hline Ecosystems are resilient & Ecosystems are delicately balanced \\
\hline Humans are separate from nature & Humans are part of nature \\
\hline Nature should be exploited for human material benefit & We must respect and protect nature, nature has intrinsic value \\
\hline $\begin{array}{l}\text { Environmental problems can be solved by analytic/scientific } \\
\text { reasoning and technology }\end{array}$ & Environmental problems can only be solved by holistic approaches. \\
\hline
\end{tabular}

While ideologies are a dominant factor in environmental decision making, they are rarely discussed. A more comprehensive model of participation should include ideological considerations.

\subsection{Cognition}

Perception, memory and reasoning affect stakeholder participation. An enormous amount of research attention has been directed toward the understanding the various 'errors' of perception. The following paragraphs provide an account of the most widely researched perceptual difficulties.

Confirmation bias is the tendency for people to selectively favour information that verifies their previous beliefs. In environmental problem solving, this bias is demonstrated extensively. For example Whitmarsh (2011) found that people sceptical about climate change favoured information sources which validated their attitudes, which in turn affected their tendency to engage or disengage in debates. Such biases are typical of false positives or "type 1 ” error.

An associated perceptual error is the illusion that two phenomena are related when in fact 
they are not. A common example of this is when two rare occurrences are correlated with one another. For instance, the common misconception that minority groups are more prone to violent behaviour may be attributed to an illusory correlation between statistically small groups and rare behaviours. Illusory correlations are characteristic of stereotypical behaviour and indicate false negatives or "type 2" error.

A final cognitive consideration relates to the observation that environmental problems may be perceived, or "framed" in numerous, and sometimes quite contrasting ways. For example, a contaminated site problem may be framed as a historical failure of the regulatory regime, an opportunity, a health threat, or an expense. The way that a problem is framed can have significant implications for the type of information that is sought and the possibilities for stakeholder participation (Leschine, Lind, \& Sharma, 2003). Framing effects generate "type 3" errors, or efforts to solve the "wrong problem” (Dunn, 2001).

Ideally stakeholder participation serves to correct these errors of perception, or at least to clarify the different perspectives on any given problem. While cognition is fundamental to stakeholder participation it is only meaningfully included in the deliberative model, cognition is assumed to be perfect in the information model, and is not included at all in the power model.

\subsection{Emotion}

Emotions underlie much of our behaviour, environmental or otherwise. A wide variety of literature increasingly supports the view of recognising and embracing emotion as both an important component of learning and a potent decision making tool (Baumeister, Vohs, DeWall, \& Zhang, 2007; Harvey, 2009; Quartz, 2009). While cognition has historically been separated from affective behaviours, increasingly, the literature has emphasised emotion as a core component of adaptive decision making (Berthoz, 2006; Schwarz, 2002; Paul Slovic, Finucane, Peters, \& MacGregor, 2004). In the past 10 years there has been a substantial shift in orientation in the behavioural sciences, in what has become known as "the emotions revolution" (Weber \& Johnson, 2009). Emotions have been cited as an alternative "affective rationality”, used to guide decision making (P. Slovic, Finucane, Peters, \& MacGregor, 2002).

Emotions serve four distinct functions in environmental problem solving (Peters, Västfjäll, Gärling, \& Slovic, 2006; Weber \& Johnson, 2009). First, emotions act as a spotlight, targeting specific problem components for deeper analysis. Secondly, emotions act as a source of information, positive and negative past associations contribute to decisions (Schwarz, 2002). Thirdly, emotions act as a "common currency", establishing whether something is good or bad (Paul Slovic et al., 2004). Finally, emotions act as motivator, for example fear can instil the motivation to escape a perceived threat, anger may motivate vengeance behaviour (Weber \& Johnson, 2009).

To be effective, stakeholder participation should allow for the expression of emotion (Harvey, 2009). Stakeholders may exhibit a wide variety of emotions during the course of resolving an environmental problem. While a number of theories of emotion have been developed, Robert Plutchik’s (2001) circumplex model has been widely adopted. Plutchik (2001) contends that 
there are eight primary emotions: Fear, anger, sadness, joy, disgust, trust, anticipation, and surprise. All eight primary emotions may therefore be anticipated. As noted earlier, stakeholder participation is frequently emotive, something information, power, and deliberative theories fail to recognise.

\subsection{Social factors}

Social factors are well-understood as being influential in stakeholder participation. For example people may be more likely to attend public meetings if their friends or spouses attend, or may be inhibited from attending if they feel unwelcome. Social trust can have a significant effect, for example Danielson et al. (2008) discovered that a close relationship between a stakeholder and project sponsor caused a third stakeholder to distrust the process and withdraw. Social factors can be significant, but the power model, the information flow, and the deliberative model fail to acknowledge them.

\section{Case Study: Fruitgrowers Chemical Company Remediation, Mapua, New Zealand}

Most studies of stakeholder participation have been performed solely on formal participation exercises. In contrast, we wished to explore how stakeholders participated throughout the course of an actual environmental problem solving exercise. To do so we investigated the cleanup of the former Fruitgrowers Chemical Company (FCC) in Mapua, historically New Zealand's most contaminated site.

\subsection{Case overview}

The Fruitgrowers Chemical Company (FCC) formed in 1931 producing a variety of organochlorine pesticides such as DDT, DDD and dieldrin. FCC began as a highly revered operation (PCE, 2008). By the late 1970s the plant was making 84 different pesticides, herbicides, insecticides and fungicides, however, with increased awareness of the toxicity and persistence of these compounds a band of dissenters formed opposing the operation. In the mid 1980's stronger environmental regulation and increasing dissent caused closure of the plant.

In the early 1990s the scale and consequences of the toxic site became increasingly evident. However, no party was willing to accept responsibility for the contamination - the owner believed that the operation had been permitted by the government, and the Crown believed that the polluter should pay. The resulting stalemate lasted for nearly 10 years until the Crown took over responsibility for the land. The site then became an "orphan contaminated site", meaning no party was identified as capable of funding the remediation of the site (PCE, 2008). The site was classified as New Zealand's most contaminated.

Two separate remediation attempts were developed for the site. In 1996, with very little public consultation, an engineering (cap and bund) solution was proposed and consents were granted. Although most neighbours were satisfied that finally something was being done, a national environmental group (Royal Forest and Bird Protection Society - "Forest and Bird") appealed the decision on the grounds that it did not represent the most effective long-term solution and the risk of failure was high. The appeal was sufficient to halt the plan. In 1999, 
the Ministry for the Environment allocated funding to a decontamination programme. Following a series of trials a remediation contract was awarded to a local novel technology Mechanochemical Dehalogenation (MCD). Consents were again appealed by environmental NGOs (Forest and Bird, and Greenpeace), purely on safety concerns - the plant was novel and largely untested. With minor modifications to the original plans, in November 2003 consents were finally granted.

Proof of Performance (POP) testing occurred in early 2004. During one of the four trials, a mechanical breakdown led to the formation and release of contaminants that included small quantities of dioxin from the POP plant. An independent scientific advisory team considered that the dioxin emissions did not represent emissions during normal operating conditions and that the problem could be eliminated. Citizens were not directly informed of the event.

Following POP trials the main contractor unexpectedly withdrew from the project. Rather than allowing the project to fail, consents for operation were transferred from the contractor to the New Zealand Ministry for the Environment. Remediation eventually began in September 2004. Ongoing problems occurred with the soil dryer and with the emissions control system (PCE, 2008). Although the scientific advisory panel were aware of problems, they did not inform stakeholders. Progressive issues led to substantial time and cost overruns.

The remediation was completed in 2008, nearly three times longer than originally anticipated. Yet concerns remained about the effectiveness and safety of the cleanup. In mid 2008 a report from the Government's environmental watchdog, the Parliamentary Commissioner for the Environment, raised serious flaws in the technical operation and management (PCE, 2008). Citizens were shocked to discover major issues had been suppressed. Government sanctioned reports tried to dampen community fears and claim the cleanup was an overwhelming success, however further health and worker safety reports (most recently 2012) have only increased community anxiety and distrust. Although the cleanup achieved nominal remediation goals, it did little to alleviate community safety concerns, as such it cannot be described as wholly successful.

\subsection{Methodology}

A qualitative research design was adopted which utilised four sources of evidence. Relevant sources of information for retrospective case analysis include documentation, archival records, interviews and physical artefacts (Yin, 2009, p101). Each source of evidence has relative strengths and weaknesses, for example, interview data are useful for obtaining insight into individual perceptions but may be affected by recall difficulties and "halo effects" based on perceptions of outcome (Bernard, Killworth, Kronenfeld, \& Sailor, 1984). Data collection is best employed in a complementary manner (Yin, 2009, p101), thus evidence was triangulated from multiple sources and consistencies or inconsistencies noted.

Multiple sources of information were used to elicit perspectives during the cleanup, and to understand how stakeholders participated in the problem solving process (Table 3). Because of the historical nature of the case, archival documentation was used as a primary source of evidence of each of the major perspectives. A comprehensive media analysis was undertaken 
from local, regional and national news sources. Further archival data was obtained through meeting minutes, consent hearing records, memos, emails and letters to and from municipal authorities, officially sanctioned reports. In total over 10,000 pages of archival records were investigated.

Archival records were supplemented with purposive stakeholder interviews. We began with a structured interview schedule, however during initial interviews found it too restrictive. We therefore proceeded with unstructured interviews but ensured that all stages of the cleanup were discussed. The 'unstructured' interview in qualitative research methodology is not strictly unstructured, instead it may be characterised as flexibly structured with the express purpose of uncovering unanticipated knowledge (Hesse-Birber \& Levy, 2003; Warren \& Karner, 2007).

Interviews were conducted with a range of stakeholders including project management staff, municipal authorities, indigenous representatives, scientific and technical representatives, environmental interest groups, and locally affected people. Although persistent requests were made to Ministry for the Environment officials, interviews were not forthcoming. In total, 17 people were interviewed in dialogues that lasted between one and four hours. Following the interview, interviewees were invited to provide any additional information. A variety of participants provided journals, physical artefacts, notes, and letters.

Data was analysed by coding into "critical incidents", events characterised by their significance to participants or their substantial effect on the project outcome. Perspectives on critical incidents were further categorised according to characteristics according to Plutchik's (2001) primary emotions. The following provides examples of ideological, cognitive, emotional and social characteristics exhibited during the cleanup.

Table 3. Sources of evidence for each of the designated perspectives

\begin{tabular}{|c|c|c|}
\hline Stakeholder Perspective & Sources of evidence & $\begin{array}{l}\text { Number of } \\
\text { interviewees }\end{array}$ \\
\hline Local municipality & $\begin{array}{l}\text { Technical reports, internal memos, correspondence records, press releases, } \\
\text { meeting minutes, news reports, interviews }\end{array}$ & 2 \\
\hline Directly affected public & $\begin{array}{l}\text { Correspondence records, hearing submissions, complaint forms, news reports, } \\
\text { community meeting minutes, task force minutes, interviews }\end{array}$ & 6 \\
\hline Local community & $\begin{array}{l}\text { Correspondence records, hearing submissions, complaint forms, news reports, } \\
\text { community meeting minutes, task force minutes, interviews }\end{array}$ & 2 \\
\hline Indigenous representatives & Hearing submissions, correspondence records, official reports, interviews & 2 \\
\hline $\begin{array}{l}\text { Technical and scientific } \\
\text { experts }\end{array}$ & Technical reports, meeting minutes, official reports, interviews & 2 \\
\hline Environmental NGOs & $\begin{array}{l}\text { Correspondence records, hearing submissions, news reports, task force minutes, } \\
\text { interviews }\end{array}$ & 1 \\
\hline Workers & Meeting minutes, official reports, news reports, interviews & 1 \\
\hline Ministry for the Environment & $\begin{array}{l}\text { Hearing submissions, meeting minutes, correspondence, press releases, news } \\
\text { reports, official reports }\end{array}$ & 0 \\
\hline
\end{tabular}




\section{Mll Macrothink}

\section{Results}

\subsection{Ideological characteristics}

Largely Imperial typologies were exhibited in the Mapua case, which placed a high emphasis on fiscal accountability, high empowerment of the technoscientific paradigm, and low engagement and empowerment of other parties. Genuine empowerment of the Arcadian perspective only manifested during the two resource consent hearings, which created an adversarial context rather than a context which facilitated the generation of mutual concern and understanding. Mapua was thus typical of an erroneous fight between competing ideologies, much to the detriment of those most affected.

\subsection{Cognitive characteristics}

Typical of a technoscientific investigation, much effort was placed on accurately estimating important parameters and predicting the consequences of action strategies. High emphasis was placed on objective, external understanding, on the precise analysis of risk and the control of external variables. Expertise was heavily relied upon to ascertain the likely contaminants present, viable remediation strategies, appropriate decontamination levels and cleanup objectives. For example, health related evaluations were principally undertaken through a Total Hazard Index (THI). The THI was analysed by experts, who attempted to isolate all of the most problematic compounds and estimate exposures. While being potentially useful as part of a programme for estimating possible health effects, the THI was relied on as the primary compliance measure, and other forms of knowing were marginalised. The resulting situation was one of epistemological competition between regulatory authorities and those most affected, not stakeholder participation.

Technology vendors, project sponsors and experts demonstrated similar cognitive bias, overconfidence in the performance of the technology. For example, the site auditor endorsed the technology at the consent hearing, stating ${ }^{1}$ :

I am satisfied that the treatment method can destroy the DDT and dieldrin+aldrin contaminants which are of most importance at the FCC site.

Later, however, following problems emerging with the novel technology, the site auditor reflects ${ }^{2}$ :

Note that general experience is that developing any new process is far more difficult than expected at the outset - in hindsight what we are seeing here is not unexpected, and the need to keep doing tests and adding safeguards and process steps is probably not unexpected (although the process did appear delightfully simple at the outset).

This confidence was shared neither by environmental NGOs, nor by many members of the public. Problems were only conveyed to members of the public and environmental NGOs several years after they occurred, through media expose. Thus cognitive biases of project sponsors stimulated non-disclosure of problems and resulted in stakeholder outrage.

\footnotetext{
${ }^{1}$ Statement of evidence from site auditor at resource consent hearing, 22 August 2003.

2 Email from site auditor to Ministry for the Environment representative, 2 August 2004.
} 
In addition to type $1 \& 2$ cognitive bias, framing differences occurred throughout the cleanup process, but most evidently when Imperial and Arcadian paradigms clashed during the two consent hearings. For instance, at the first resource consent hearing, Forest \& Bird suggested that cap and bund was not remediation, and that the proposed solution did not constitute sustainable management of the land since it left a significant risk for future generations ( $F \& B$, 1996). Another example of framing differences occurred at the second resource consent hearing, where project sponsors refer only to odorous discharges and dust (T\&T, 2003), in contrast to Greenpeace concerns of toxic emissions and dioxin ${ }^{3}$. Major framing differences were settled by hearing commissioners rather than through deliberative discourse.

\subsection{Emotional Factors}

A variety of emotions were exhibited by stakeholders during the course of the cleanup. The following paragraphs provide examples of Plutchik's eight primary emotions during the course of the cleanup.

Many local residents feared the potential effects of the remediation strategy, several submissions to the resource consent expressed significant concerns, one asking "can the safety be absolutely guaranteed?"4 Environmental NGOs Greenpeace and Forest \& Bird were also principally concerned about safety and the effects of air discharges from the technology. To alleviate these concerns an agreement was reached to limit the temperature of the drier to $110^{\circ} \mathrm{C}$ which would inhibit the volatilisation of contaminants. However, during implementation it became evident that the $110^{\circ} \mathrm{C}$ limit was impractical. Closed discussions between expert peer review panel members led to the condition being relaxed, neither Greenpeace nor Forest \& Bird were notified. Due to lack of involvement, fear became disgust.

Anger erupted at various times during the course of the project, one of the most significant examples are and following the news expose when citizens felt they were being deceived. A citizen opined ${ }^{5}$ :

These reports present a sanitised version of the monitoring results in very technical lingo. Do they mention the obvious breaches of the resource consent? No. Do they explain the significance of the monitoring results and exceedences of guidelines? No....Local folks want to know what $172,454 \mathrm{~g} / \mathrm{m} 2 /$ month of DDT means. Should our children be outdoors breathing this stuff?

In response, the Environment and Planning manager of the local council directed the citizen to a technical health index which had been modified several times. The citizen remained unsatisfied, and angry.

Sadness and frustration was demonstrated most evidently when Environmental NGOs appealed the resource consent decision. Local residents were frustrated that parties not

\footnotetext{
${ }^{3}$ Greenpeace submission on application for resource consent, 24 July 2003.

${ }^{4}$ Submission on application for resource consent from local resident, 18 July 2003

${ }^{5}$ Letter to the editor from A. Dickinson, The Nelson Mail. 5 July 2007.
} 
directly affected were causing delays to the implementation. The president of the local community association commented ${ }^{6}$ :

"People have no faith in Forest and Bird anymore"

This frustration stemmed from the fact that local residents were excluded from negotiations during the appeal process. No attempt was made to remedy this frustration by project sponsors, who were also frustrated by the delays.

Through extensive interaction, members of the local community developed a strong trust relationship with the local council, who were at that time managing the project. This trust extended to the belief that technical matters would be appropriately addressed and hence that local stakeholders need not participate in technical inquiries. Hence there was little adverse reaction when a community task force was dissolved at the beginning of full-scale implementation. This trust was later found to be misguided, resulting in anger and outrage.

Disgust became evident when parties failed to act as anticipated. As a Forest \& Bird representative noted ${ }^{7}$ :

I continue to be dismayed at the lack of communication that $F \& B$ have with you... we have not ever been kept informed. This seems to me to be particularly crucial in view of the laxness in the conditions and the huge "trust" we gave in relation to the Proof of Performance and standard setting.

Anticipation was exhibited by many stakeholders when resource consents were submitted. A long process of preparation had ensued and many anticipated the cleanup finally getting underway. Anticipation led to sadness and frustration when consents were appealed by Forest \& Bird and Greenpeace.

While significant amounts of joy may be anticipated for a project which seeks to alleviate a community concern, joy was distinctly lacking during the contaminated site cleanup at Mapua. Stakeholder happiness would have been expected at the completion of a project, however, celebrations were marred by the Parliamentary Commissioners investigation and questions that were raised toward the end of the project by investigative reporters. Nevertheless, project sponsors (MfE) and indigenous representatives did express joy that the remediation was complete. Joy was noted by indigenous representatives due to their participation as cultural monitors during the implementation phase and their perception that they had performed their role well. However, the general lack of joy exhibited during the project indicates that processes could have been managed better.

\subsection{Social factors}

Social factors had a considerable influence on participation. For example during the cleanup, official public meetings were attached to regular meetings of the local community association, a group who had been strong supporters of the cleanup. However, some residents adjacent to

\footnotetext{
6 "Residents angry over delays to Mapua site clean-up". The Christchurch Press. 4 November 2003

${ }^{7}$ Email from Forest and Bird representative to project manager, 15 June 2004.
} 
the site believed the association had let them down, and were deeply aggravated by the associations' position. This antagonism led to conflict during community meetings, and consequently some adjacent residents stopped attending. Furthermore, since updates relating to the site were attached to sometimes lengthy regular meetings of the community association, some residents and NGOs were deterred from attending due to disinterest.

\section{Reframing Stakeholder Participation in Environmental Problem Solving - The Empathy, Understanding and Empowerment Model}

As we have seen, stakeholder participation is characterised by ideological differences, cognitive and emotional factors, and social considerations. None of these factors are adequately addressed by current models of stakeholder participation. Deriving from our case, generalised from other environmental problem solving situations, and developed through a collaborative inquiry with 10 experienced facilitators, it is possible to discern three primary themes of 'empathy', 'understanding' and 'empowerment' divided along two dimensions of self and others which account for the psychological underpinnings of participation (Figure 2).
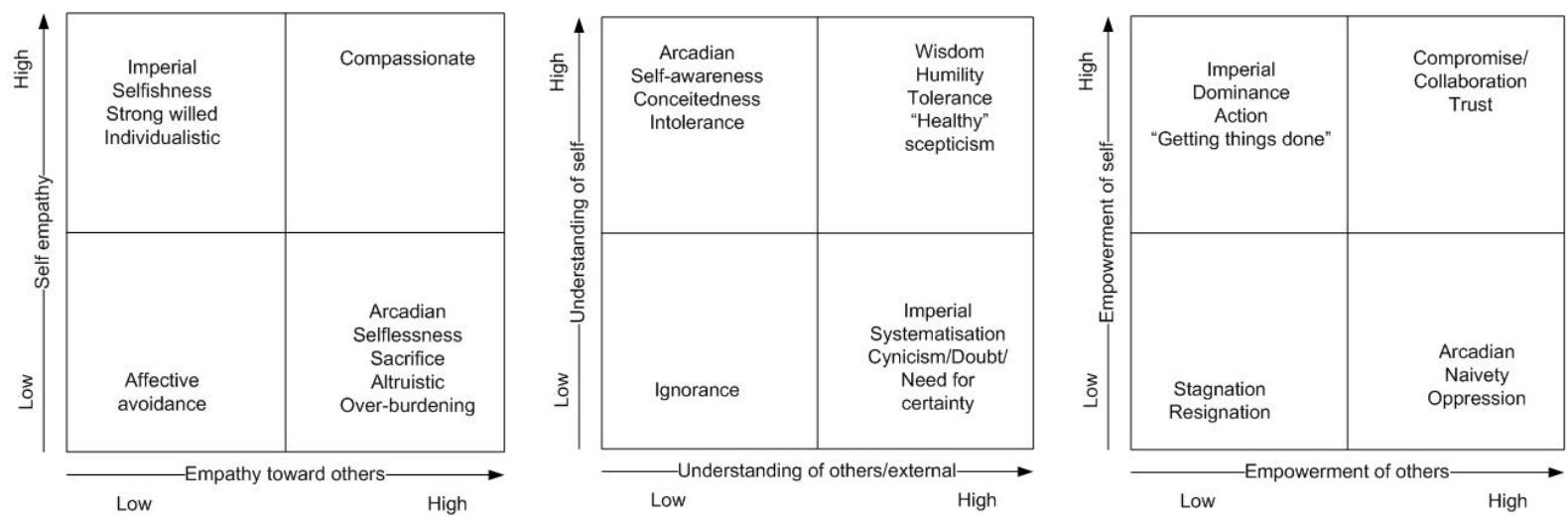

Figure 2. Three themes and two dimensions of the psychology of participation in environmental problem solving

\subsection{Empathy}

Empathy here refers to the general level of emotional concern. Empathy helps to form the foundations of beneficent and just social structures (Gerdes, Segal, \& Lietz, 2010). Traditionally, empathy has been aligned with altruistic behaviours and contrasted with selfish motivations - empathy is usually thought of as "putting oneself in another person's shoes". As such empathy is sometimes considered tantamount to imitation of others (e.g. Iacoboni, 2009). While imitation appears to be one aspect to empathy, fuller accounts by contemporary ethologists suggest the concept is heavily related to emotional connectedness (de Waal, 2008). However in contrast with contemporary ethologists who suggest that altruism and selfishness are opposing characteristics of empathy (de Waal, 2008), in fact they may be considered to be closely linked - altruism being emotional concern for others directly and selfishness simply being emotional concern for our (future) selves.

In environmental problem solving empathy is fundamental to the development of productive 
stakeholder participation. Strong empathic concern for oneself without concern for others can lead to strong willed, uncompromising, archetypal Imperial attitudes - selfish needs come first. Lack of concern toward others results in parties talking past each other, listening poorly or not listening at all, and being overly sensitive to their own needs. Conversely, those with overwhelming concern for others are more closely aligned with the Arcadian paradigm, commonly displaying altruistic or selfless behaviours - the needs of others come first. While these behaviours appear to be prosocial, an inability to adequately acknowledge personal needs means that demonstrations of selflessness can quickly become viewed as self-sacrificing or overly burdensome. Those with low levels of empathy for oneself and for others demonstrate affective avoidant behaviours or inaction. In contrast, individuals with both high levels of self concern and high concern for others exhibit more compassionate behaviour, unencumbered by thoughts of superiority or inferiority.

\subsection{Understanding}

Understanding pertains to effective knowledge, the cognitive ability to remember and recognise patterns. Usually understanding is considered solely in terms of external understanding - knowledge of the world around us. However, it has long been recognised that self knowledge also provides a foundational role in understanding, reinforced by psychologists beginning with Carl Jung (Miller, 1999). Including the psychological world blurs the distinction between reality (concrete 'things' that can be independently measured) and the abstract (ideas which may be wholly subjective), however it enables a more comprehensive picture of environmental problem solving to be developed which includes common psychological barriers. Thus, following Miller (1999), understanding relates to knowledge of ourselves, others and the world around us.

Understanding is fundamentally important to effective stakeholder participation. High external understanding is typical of the materialistic techno-scientific paradigm which emphasises systematisation. Paradoxically, while proffering scepticism, a high level of external understanding can lead to an increasing need for certainty - as exhibited by the stubbornness of adherence to dominant customs and traditions by conservatives and scientists (Kuhn, 1962). Self understanding is largely neglected by the Imperial ideology but highly regarded by the Arcadian. High self understanding is increasingly recognised as important to the effective coordination of teams (Goleman, 2004), but is also essential for collaborative environmental problem solving. High levels of self understanding can lead to self-awareness, but may also be accompanied by a certain level of conceitedness and intolerance. Low levels of both self and external understanding are tantamount to ignorance, and conversely, high levels of both are correlated with humility, tolerance, "healthy" scepticism and wisdom.

\subsection{Empowerment}

Empowerment pertains to agency, the ability to act. Empowerment translates empathy and understanding into action. Empowerment is usually considered self agency, the capacity to promote one's own ideas and ideologies, to act on one's will. But empowerment also relates to the empowerment of others, service which enables others to act. The whole 'art' of facilitation, for example, is the precise ability to enable a group of other people to achieve 


\section{Macrothink}

their own purpose (Hunter, Thorpe, Brown, \& Bailey, 2007). Thus empowerment is not only about self agency, it includes participating in activities which enable the agency of others.

Comparatively, Imperialists exhibit high desires for self agency whereas Arcadians are more likely to help others. High levels of self empowerment can lead to action, to "getting things done”, but may be accompanied by domineering behaviour and the wielding of power. High propensity to help others can encourage pro-social behaviours, but may also cater to oppressive regimes or be considered naive and ineffective. Low levels of both self and other empowerment leads to stagnation and resignation, whereas high levels of both can generate sensible compromise solutions, love, collaboration and trust.

\subsection{Model Summary}

Together, high levels of self and externalised empathy, understanding and empowerment are the most effective means of solving environmental problems. In individuals, highly developed levels of empathy, understanding and empowerment may be considered "whole person” environmental problem solving (Figure 3). In contrast to the whole person, Arcadians exhibit greatly reduced capacity for self-empathy and self-empowerment, and greatly reduced capacity for external understanding. Alternatively, Imperialists exhibit greatly reduced capacity for empathy and empowerment of others, and for introspective understanding. Rather counter-intuitively, both Arcadians and Imperialists exhibit reduced capacity compared to the whole person in relation to their most treasured attributes - the whole person is more caring than the Arcadian, more knowledgeable and powerful than the Imperialist etc... The reasons for improved performance may be attributed to a greater cognitive balance, to reduced anxiety and self-protectiveness, to a realistic pairing of what is and what is perceived, to a curiosity and humility which enables new ideas to be generated or perceived, and to a fearlessness which promotes action and challenges old ideas.

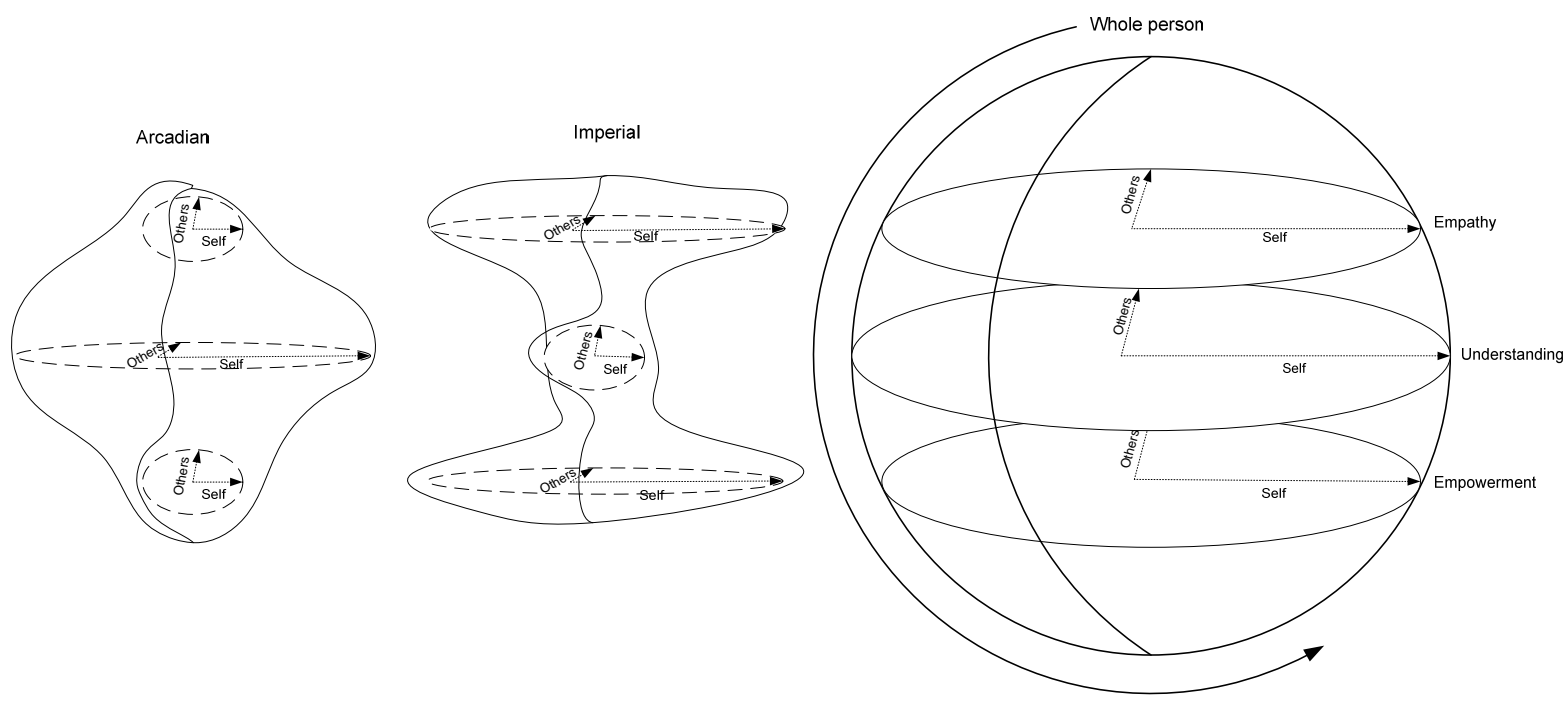

Figure 3. Typographical representation of Arcadian, Imperial and Whole person decision making in environmental problem solving 
The Whole person model of stakeholder participation emphasises balanced development of problem solving attributes. It reminds us that the capacity to care, understand, and empower, both ourselves and others, is not fixed, it may be developed. While there has been much research on promoting aspects of the Whole person such as external understanding, only recently have empathy and self understanding been seriously considered as essential for human development. Increasing research is dedicated to promoting emotional literacy, and a raft of tools are now available (e.g. Cherniss \& Goleman, 2001). With effort, it has been demonstrated that much personal progress can be made (Goleman, 2004).

While the three characteristics of empathy, understanding, and empowerment have been defined individually, interlinkages between the concepts are clearly evident. The willingness to empower others for instance is necessarily preconditioned by feelings of empathy - the autonomous motivation to help relies on empathy (Pavey, Greitemeyer, \& Sparks, 2012). Without empathy, the tendency toward dismissing other perspectives and empowering one's own perspective is strong. Moreover, empathy is required to comprehend differences in understanding between perspectives. Without empathic connection, a fixation on one's own knowledge can limit opportunities for learning about different perspectives and thus gain a deeper understanding of the problem context. Furthermore, a certain level of problem understanding is necessary to enable the power to act, and actions promote additional inquiry and reflection which may stimulate novel and unanticipated feelings. Thus, the capacity to participate optimally in environmental problem solving is constantly changing, meaning that interactions between individuals and groups must continually adapt.

The "whole person" may be regarded as an idealised participant (project sponsor or stakeholder) with the characteristics of high empathy, understanding and empowerment of self and others. Clearly however, such a person rarely exists. In view of this deficit how can stakeholder participation be managed? The following provides ten suggestions for stakeholder interaction:

1) Develop connections early and equally. Are all stakeholders involved in discussions? Regaining empathic connections and trust is much more difficult after it has been lost. Ensure that all relevant stakeholders are considered early in the project.

2) Promote connections within and between stakeholders. Conflict between stakeholders can derail collaborative efforts and stifle participation. Effort should be made to minimise or manage conflict.

3) Promote open disclosure of feelings. Are feelings being discussed or avoided? The tendency of the technoscientific paradigm is to focus on external problem components and avoid discussions of feelings. Such a stance marginalises stakeholders and may lead to suppression and resentment. Open disclosure of feelings can be aided by assisted storytelling (Thorpe, 2011) and small group interaction (Hunter et al., 2007).

4) Understand multiple scenarios with all stakeholders. Develop an understanding of the best and worst outcomes in conjunction with other stakeholders.

5) Use experienced, independent facilitators. Experienced facilitators have been trained to 


\section{Macrothink}

detect and dispel power imbalances during discourse. They may thus aid participation issues such as stakeholder capture and outcome manipulation.

6) Be empathetic to the needs of others. Do some participants have special needs in order to participate? E.g. low income families, families with young children requiring childcare. Search for solutions with other stakeholders.

7) Search for ways to involve others. Develop mutual responsibilities and accountabilities. For example, a local community member could have assisted compliance officers at Mapua. Try to build capacity.

8) Give recognition to actions. Develop a culture of gratitude for participation.

9) Enable time for reflection and ask for feedback. Are proposed timeframes too tight to gain meaningful feedback from stakeholders? If so, empathy may be lost and it may be best to adjust schedules.

10) Review thoughts, feelings and actions regularly. Some questions that are useful to reflect on include: How well are uncertainties understood? How are stakeholders feeling? What is anticipated? What is happening?

\section{Conclusion}

A detailed case investigation has revealed the need for inclusion of psychosocial considerations in stakeholder participation during environmental problem solving. In particular, ideological characteristics, cognitive factors, emotion, and social attributes all strongly influence how and why participants choose to be involved, yet they are rarely considered in current models of participation. Instead a new model of participation has been developed with three principal themes of empathy, understanding and empowerment. For effective participation, high self-empathy, understanding and empowerment is necessary in addition to high empathy, understanding and empowerment toward others. High capacity for empathy, understanding and empowerment generates the "whole person" participant, and promotes open disclosure of emotion, mutual concern, efficient solution finding and collaborative action. Thus for effective management of stakeholder participation processes, consideration of emotional, as well as cognitive and action oriented characteristics is necessary.

\section{Acknowledgements}

The authors would like to acknowledge the contribution of case study participants; collaborative inquiry participants, especially Dale Hunter, Stephen Thorpe, Nardene Berry, Margaret Hansford and Joan Firkins; Professor Alan Miller; colleagues Idil Gaziulusoy, Richard Donnelly, and Gaya Gamage; and the two anonymous peer reviewers who have helped to greatly improve the paper.

\section{References}

Abels, G. (2007). Citizen involvement in public policy-making: Does it improve democratic legitimacy and accountability? The Case of pTA. Interdisciplinary Information Sciences, 
13(1), 103-116.

Arnstein, S. R. (1969). A Ladder of Citizen Participation Journal of the American Planning Association, 35(4), 216 - 224

Baumeister, R. F., Vohs, K. D., DeWall, C., \& Zhang, L. (2007). How Emotion Shapes Behavior: Feedback, Anticipation, and Reflection, Rather Than Direct Causation. Personality and Social Psychology Review, 11(2), 167-203.

Bernard, H. R., Killworth, P., Kronenfeld, D., \& Sailor, L. (1984). The problem of informant accuracy: The validity of retrospective data. Annual Review of Anthropology, 13, 495-517.

Berthoz, A. (2006). Emotion and reason: The cognitive science of decision making. Oxford: Oxford University Press.

Birkland, J. (1999). “Community participation” in urban project assessment (an ecofeminist analysis). In B. Martin (Ed.), Technology and Public Participation. Wollongong: University of Wollongong.

Bishop, P., \& Davis, G. (2002). Mapping Public Participation in Policy Choices. Australian Journal of Public Administration, 61(1), 14-29.

Cherniss, C., \& Goleman, D. (2001). The emotionally intelligent workplace : how to select for, measure, and improve emotional intelligence in individuals, groups, and organizations. San Francisco: Jossey-Bass.

Collins, K., \& Ison, R. (2009). Jumping off Arnstein's ladder: Social learning as a new policy paradigm for climate change adaptation. Environmental Policy and Governance, 19(6), 358-373.

Cotgrove, S. (1982). Catastrophe or cornucopia: The environment, politics and the future. Chichester: Wiley.

Creighton, J. L. (2005). The public participation handbook. San Francisco: Jossey-Bass.

Danielson, S., Santos, S. L., Webler, T., \& Tuler, S. P. (2008). Building and breaking a bridge of trust in a Superfund site remediation. International Journal of Global Environmental Issues, 8(1-2), 45-60.

de Waal, F. B. M. (2008). Putting the Altruism Back into Altruism: The Evolution of Empathy. Annual Review of Psychology, 59(1), 279-300.

Delgado, A., Kjolberg, K. L., \& Wickson, F. (2011). Public engagement coming of age: From theory to practice in STS encounters with nanotechnology. [Article]. Public Understanding of Science, 20(6), 826-845.

Dunn, W. N. (2001). Using the method of context validation to mitigate type III errors in environmental policy analysis. In M. Hisschemöller, R. Hoppe, W. N. Dunn \& J. R. Ravetz (Eds.), Knowledge, power and participation in environmental policy analysis (pp. 417-436). New Jersey: Transaction Publishers. 
F\&B. (1996). Submission on RM960599, NN960452, NN960453, NN960454: Tasman Branch. Royal Forest and Bird Protection Society of New Zealand.

Fiorino, D. J. (1990). Citizen Participation and Environmental Risk: A Survey of Institutional Mechanisms. Science Technology Human Values, 15(2), 226-243.

Funtowicz, S. O., \& Ravetz, J. R. (1993). Science for the post-normal age. Futures, 25(7), 739-755.

Gerdes, K. E., Segal, E. A., \& Lietz, C. A. (2010). Conceptualising and Measuring Empathy. British Journal of Social Work, 40(7), 2326-2343.

Goleman, D. (2004). What Makes a Leader? Harvard Business Review, 82(1), 82-91.

Habermas, J. (1984). The theory of communicative action: Volume 1 - Reason and the rationalization of society (T. McCarthy, Trans.). Boston, MA: Beacon Press.

Harding, R., Hendriks, C. M., \& Faruqi, M. (2009). Environmental decision-making : exploring complexity and context Annandale, NSW: Federation Press.

Harvey, M. (2009). Drama, talk, and emotion: Omitted aspects of public participation. Science Technology and Human Values, 34(2), 139-161.

Hesse-Birber, S. N., \& Levy, P. (2003). Approaches to Qualitative Research: A Reader on Theory and Practice. New York: Oxford University Press.

Hunter, D., Thorpe, S., Brown, H., \& Bailey, A. (2007). The Art of Facilitation. Auckland: Random House.

Iacoboni, M. (2009). Imitation, empathy, and mirror neurons. Annual Review of Psychology, 60, 653-670.

IAP2. (2007). IAP2 Spectrum of public participation. from http://www.iap2.org/associations/4748/files/spectrum.pdf

Irvin, R. A., \& Stansbury, J. (2004). Citizen Participation in Decision Making: Is It Worth the effort? Public Administration Review, 64(1), 55-65.

King, C. S., Feltey, K. M., \& Susel, B. O. (1998). The Question of Participation: Toward Authentic Public Participation in Public Administration. Public Administration Review, 58(4), 317-326.

Kinney, A. G., \& Leschine, T. M. (2002). A procedural evaluation of an analytic-deliberative process: The Columbia River Comprehensive Impact Assessment. Risk Analysis, 22(1), 83-100.

Kuhn, T. (1962). The structure of scientific revolutions. Chicago: University of Chicago Press.

Laird, F. N. (1993). Participatory analysis, democracy, and technological decision making. Science, Technology, \& Human Values, 18(3), 341-361. 


\section{Macrothink}

Leschine, T. M., Lind, K. A., \& Sharma, R. (2003). Beliefs, values, and technical assessment in environmental management: Contaminated sediments in Puget Sound. Coastal Management, 31(1), 1-24.

Lockie, S. (2001). SIA in review: setting the agenda for impact assessment in the 21st century. Impact Assessment Project Appraisals, 19(4), 277-287.

Mander, J. (1991). In the Absence of the Sacred: The Failure of Technology and the Survival of the Indian Nations: Sierra Club Books.

Miller, A. (1999). Environmental problem solving : psychosocial barriers to adaptive change. New York: Springer.

NRC. (2008). Public Participation in Environmental Assessment and Decision Making Washington DC: National Research Council. Panel on Participation in Environmental Assessment and Decision Making. Committee on the Human Dimensions of Global Change. Division of Behavioral and Social Sciences and Education. National Academies Press.

O'Faircheallaigh, C. (2010). Public participation and environmental impact assessment: Purposes, implications, and lessons for public policy making. Environmental Impact Assessment Review, 30(1), 19-27.

Palerm, J. R. (2000). An Empirical-Theoretical Analysis Framework for Public Participation in Environmental Impact Assessment. Journal of Environmental Planning and Management, 43(5), 581-600.

Pavey, L., Greitemeyer, T., \& Sparks, P. (2012). "I help because I want to, not because you tell me to": Empathy increases autonomously motivated helping. Personality and Social Psychology Bulletin, 38(5), 681-689.

PCE. (2008). Investigation into the remediation of the contaminated site at Mapua. Wellington: Parliamentary Commissioner for the Environment.

Peet, J. (2006). Systems Thinking and Common Ground. International Journal of Transdisciplinary Research, 1(1), 88-99.

Pepper, D. (1996). Modern environmentalism: An introduction. London: Routledge.

Peters, E., Västfjäll, D., Gärling, T., \& Slovic, P. (2006). Affect and decision making: A "hot" topic. Journal of Behavioral Decision Making, 19(2), 79-85.

Plutchik, R. (2001). The Nature of Emotions: Human emotions have deep evolutionary roots, a fact that may explain their complexity and provide tools for clinical practice. American Scientist, 89(4), 344-350.

Pretty, J. N. (1995). Participatory learning for sustainable agriculture. World Development, 23(8), 1247-1263.

Quartz, S. R. (2009). Reason, emotion and decision-making: risk and reward computation with feeling. Trends in Cognitive Sciences, 13(5), 209-215. 


\section{Macrothink}

Environmental Management and Sustainable Development

ISSN 2164-7682

2012, Vol. 1, No. 2

Reed, M. S. (2008). Stakeholder participation for environmental management: A literature review. Biological Conservation, 141(10), 2417-2431.

Reed, M. S., Dougill, A. J., \& Taylor, M. J. (2007). Integrating local and scientific knowledge for adaptation to land degradation: Kalahari rangeland management options. Land Degradation and Development, 18, 249-268.

Rowe, G., \& Frewer, L. J. (2005). A Typology of Public Engagement Mechanisms. Science, Technology, \& Human Values, 30(2), 251-290.

Santos, S. L., \& Chess, C. (2003). Evaluating citizen advisory boards: The importance of theory and participant-based criteria and practical implications. Risk Analysis, 23(2), 269-279.

Schwarz, N. (2002). Emotion, cognition, and decision making. Cognition and Emotion, 14, 433-440.

Slovic, P., Finucane, M. L., Peters, E., \& MacGregor, D. G. (2002). The affect heuristic. In D. G. T. Gilovich, \& \& D. Kahneman (Eds.), Heuristics and biases: The psychology of intuitive judgment (pp. 397-420). New York: Cambridge University Press.

Slovic, P., Finucane, M. L., Peters, E., \& MacGregor, D. G. (2004). Risk as Analysis and Risk as Feelings: Some Thoughts about Affect, Reason, Risk, and Rationality. Risk Analysis, 24(2), 311-322.

Stirling, A. (2008). "Opening up" and "closing down": Power, participation, and pluralism in the social appraisal of technology. Science Technology and Human Values, 33(2), 262-294.

Stringer, L. C., Reed, M. S., Dougill, A. J., Rokitzki, M., \& Seely, M. (2007). Enhancing participation in the implementation of the United Nations Convention to Combat Desertification. Natural Resources Forum, 31, 198-211.

Sunstein, C. R. (2006). When crowds aren't wise. Harvard Business Review, 84(9), 20-21.

T\&T. (2003). Thiess Services Pty Ltd. FCC Mapua Site Remediation, Assessment of Environmental Effects. Auckland: Tonkin \& Taylor

Thorpe, S. (2011). Sense of Place and Emotional Connections Using Collaborative Storytelling in Second Life. International Journal of Information and Education Technology, 1(4), 292-297.

Tritter, J. Q., \& McCallum, A. (2006). The snakes and ladders of user involvement: Moving beyond Arnstein. Health Policy, 76(2), 156-168.

Ventriss, C., \& Kuentzel, W. (2005). Critical theory and the role of citizen involvement in environmental decision making: A re-examination. International Journal of Organization Theory and Behavior, 8(4), 519-539.

Warren, C. A. B., \& Karner, T. X. (2007). Discovering Qualitative Methods: Field Research, Interviews, and Analysis. New York: Oxford University Press. 


\section{Macrothink}

Environmental Management and Sustainable Development

ISSN 2164-7682 2012, Vol. 1, No. 2

Weber, E. U., \& Johnson, E. J. (2009). Mindful judgment and decision making, Annual Review of Psychology (Vol. 60, pp. 53-85).

Webler, T. (1995). Right discourse in public participation: An evaluative yardstick. In O. Renn, T. Webler \& P. Wiedermann (Eds.), Fairness and competence in public discourse: Evaluating models for environmental discourse (pp. 35-86). Dordrecht, Netherlands: Kluwer.

Webler, T., Tuler, S., \& Krueger, R. O. B. (2001). What Is a Good Public Participation Process? Five Perspectives from the Public. Environmental Management, 27(3), 435-450.

Whitmarsh, L. (2011). Scepticism and uncertainty about climate change: Dimensions, determinants and change over time. Global Environmental Change, 21(2), 690-700.

Worster, D. (1993). The wealth of nature : environmental history and the ecological imagination: New York : Oxford University Press.

Yin, R. K. (2009). Case Study Research: Design and Methods (4th ed.). Thousand Oaks, CA: Sage Publications.

\section{Copyright Disclaimer}

Copyright reserved by the author(s).

This article is an open-access article distributed under the terms and conditions of the Creative Commons Attribution license (http://creativecommons.org/licenses/by/3.0/). 